\title{
Sources of color variation on firing porcelain
}

\section{W.J. O'Brien \\ K.-S. Kay \\ K.M. Boenke \\ C.L. Groh}

Department of Biologic

and Materials Sciences

School of Dentistry

The University of Michigan

Ann Arbor, Michigan 48109-1078

'Department of Prosthodontics

School of Dentistry

Chosun University

Susuk-Dong, Kwangju, South Korea

Received May 21, 1990

Accepted April 15, 1991

This investigation was supported by

Research Grants DE-05423 and DE- 09296

from the National Institute of Dental

Research, National Institutes of Health,

Bethesda, MD 20892.

Dent Mater 7:170-173, July, 1991

Abstract-The final color matching of porcelain crowns depends upon the accuracy of the original shade matching by the dentist and variables introduced during processing. Possible sources of processing variables include thickness and color of the opaque, thickness, color, and translucency of the body and enamel layers, firing temperature, and number of firings (Miller, 1987). These processing variables can lead to an error in shade match. The purpose of this study was to quantify, in CIE $N E$ units: (1) the shade variations when the same batches are fired, (2) the shade variations between different batches, and (3) the differences in color produced by the multiple firing. Three lots of six shades of four commercial brands were included in this study. The color variation of the opaque samples (mean $\Delta \mathbb{E}$ was 0.46 ) was generally lower than that of the body/opaque samples (mean $\Delta E$ was 0.86 ). The average color variation for three different batches of the body/opaque samples was 1.44. The average color difference produced as a result of multiple firings was 1.00 after six firings, compared with the color after three firings.
$\mathrm{T}$ he preparation of porcelain restorations that match the natural dentition has been a subject of great concern for many years. There are many factors that influence the ability of the dentist and the laboratory to obtain an esthetically acceptable match. These factors have been described in detail by Miller (1987) and Preston (1983, 1985).

Barghi et al. (1985) reported discernible color changes among three batches of VMK-68 porcelain; however, the color changes were not quantified.

The effect of multiple firing on the color of dental porcelains has been identified as one factor. Previous studies (Binns, 1977; Barghi and Goldberg, 1977; Barghi and Richardson, 1978; Jorgenson and Goodkind, 1979; Barghi, 1982) have reported that repeated firings (up to ten times) did not noticeably affect the color stability of any shade tested.

Correlations of measured color differences to visual perceptions of acceptability are complex. A basic study evaluating color difference determined that there was no significant difference between perceptibility and acceptability, and that the average total CIE L*a*b* color difference $(\Delta \mathrm{E})$ for $50 \%$ perceptibility or acceptability to be approximately one unit (Kuehni and Marcus, 1979) when dyed textiles or matte paints on cardboard are being evaluated. However, acceptability judgments need to consider the intended application (Wyszecki and Stiles, 1982). For example, Ruyter et al. (1987) and Johnston and Kao (1989) have attempted to compare visual acceptability with measured color differences for resin composites using the CIE L*a*b* color system. Ruyter et al. (1987) observed in composite veneer specimens that CIE $\mathrm{L}^{*} \mathrm{a}^{*} \mathrm{~b}^{*}$ color differences lower than approximately 3.3 were acceptable. Johnston and Kao (1989) found that the average CIE $\mathrm{L}^{*} \mathrm{a}{ }^{*} \mathrm{~b}^{*}$ color difference for a match in the oral environment for composite veneers compared with teeth was 3.7. However, Johnston and Kao (1989) also noted that there was not a clear delineation between visual evaluation criteria and measured color differences. Therefore, although a $\Delta \mathrm{E}$ of 1.0 may be acceptable under "ideal" viewing condi- tions, under intra-oral conditions the limit to acceptability will be in the range of 3.3-3.7 $\triangle E$ CIE L*a*b* units.

In this study, the sample-to-sample color variation from the same batch, batch-to-batch variation for the same shade, and the color difference due to multiple firings will be determined. This is part of an overall program to measure the sources of error in each step in preparation of a porcelain restoration in $\triangle E$ units of the CIE $\mathrm{L}^{*} \mathrm{a}^{*} \mathrm{~b}^{*}$ system. With a better understanding of the sources of error, one can make improvements in the existing systems that will increase the probability of obtaining an acceptable match.

\section{MATERIALS AND METHODS}

Three batches of four commercial brands-including Ceramco II (Ceramco, Inc., Burlington, NJ), Jelenko (Jelenko Dental Health Products, Armonk, NY), Vita VMK 68 (Vident Products, Inc., Baldwin Park, CA), and Will-Ceram (Williams Dental Co., Inc., Tonawanda, $\mathrm{NY}$ ) porcelains in Vita shades A2, A3, A3.5, B2, C2, and D4-were used with six replicates.

Since we were only interested in the effects of porcelain batch, brand, and shade designation on color, the contribution of a metal backing was not studied. Therefore, the body samples were prepared on an opaque backing having the same shade designation, with thickness $(1.05 \mathrm{~mm})$ suitable to support the body and eliminate color contributions from other sources.

Opaque specimens were prepared by the mixing of $0.50 \mathrm{~g}$ of opaque powder with a few drops of distilled water. The water produced a sample with higher green strength, which was necessary for the sample to be manipulated prior to being fired. The moistened powder was placed in a mold with a diameter of 17.0 $\mathrm{mm}$ and compressed in a hydraulic press (Dake Corp., Grand Haven, MI), producing a disk approximately $1 \mathrm{~mm}$ thick. These disks were placed on a sagger tray (Jelenko Dental Health Products) covered with alumina powder (Fisher Scientific, Fair Lawn, NJ). These samples, which were made with the same batch of opaque porcelains that were used in the 
first set of body/opaque samples, were fired three times in a porcelain furnace (Cera-Mat.III, Jelrus International Corp., Hicksville, NY) at the temperatures recommended by the manufacturers and measured for color.

The body/opaque samples were prepared by placement of $0.41 \mathrm{~g}$ of body powder (moistened with distilled water) in a mold with a diameter of $17.0 \mathrm{~mm}$, then compressed in a hydraulic press. The water kept the body layer from distorting when the opaque layer was compressed. Then, a 0.50 -g quantity of opaque powder (moistened with distilled water) was placed on top of the compressed body powder, and the powders were compressed again in the hydraulic press. This procedure produced a disk having a body layer and an opaque layer $1.00 \mathrm{~mm}$ and $1.05 \mathrm{~mm}$ thick, respectively, after being fired. These samples were fired as a single unit, on a sagger tray covered with alumina powder, so that optical contact between the layers would be ensured. They were fired three times in a porcelain furnace at the temperatures recommended by the manufacturers, and color measurements were made on the body surface. The first set of samples was then fired three more times, and color measurements were made after the sixth firing.

A spectrophotometer (Color Eye with sphere geometry, Model No. M2020PL, Macbeth, Newburgh, NY) was used for reflectance measurements of color. The sample was exposed to the emission of a xenon light, with a $\mathrm{D}_{65}$ conversion filter, and the reflected light was analyzed by means of a spectrometer. The results were expressed in CIE $\mathrm{L}^{*} \mathrm{a} \mathrm{b}^{*}$ units with illuminant $\mathrm{C}$ and 1931 standard observer functions used (that is, a $2^{\circ}$ visual field). The precision of the color measurements, based upon 20 measurements of the same sample, was 0.23 $\Delta \mathrm{E}$ units.

Color differences, $\Delta \mathrm{E}$, were calculated by use of the equation below:

$\Delta \mathrm{E}=\left[\left(\Delta \mathrm{L}^{*}\right)^{2}+\left(\Delta \mathrm{a}^{*}\right)^{2}+\left(\Delta \mathrm{b}^{*}\right)^{2}\right]^{1 / 2}$

where $\Delta L^{*}, \Delta a^{*}$, and $\Delta b^{*}$ were the differences in the CIE color space parameters of the two colors.

The mean color variation of the opaque porcelain for each shade and brand was calculated as the average difference between the color coordinates of each of the six replicate samples and the mean $L^{*} a^{*} b^{*}$ of the six. The mean color variation within three batches of the body/opaque porcelain was the average difference for the three batches, when the difference for each batch was calculated as the average difference between the color coordinates of each of the six replicate samples and the mean $\mathrm{L}^{*} \mathrm{a} \mathrm{b}^{*}$ of the six for each batch. The color variations from the mean color of the body/opaque samples for three different batches was calculated as the average difference between the color coordinates of each of the 18 samples of the three batches and the mean $\mathrm{L}^{*} \mathrm{a}^{*} \mathrm{~b}^{*}$ of all 18 . Statistical analysis was performed with an analysis of variance used to study the effects of brand and shade on color variation. The color variations were compared with Tukey's Studentized Range (HSD) Test used to determine if a significant difference existed at the $95 \%$ confidence level (SAS Statistical Software, SAS Institute, Version 5.16, Cary, NC). The amount of variation was analyzed by grouping the results according to brand or shade, and then the statistical methods were used.

The color difference resulting from multiple firings was calculated as the difference between the means for the color coordinates after six firings and the means after three firings. The color differences for the color changes due to multiple firing were also grouped according to brand or shade prior to statistical analysis.

\section{RESULTS}

Shade Variations. - The color variations calculated for the opaque and for the combined body/opaque specimens (after three firings) are given in Tables 1 and 2 . The variation for the opaque shades (mean $\Delta \mathrm{E}$ was 0.46 ) was generally lower than that of the body/opaque combinations (mean $\Delta \mathrm{E}$ was 0.86 ). For the opaque samples, the color variation does not differ significantly among the four brands of porcelain but does differ with the shade. Shade appears to affect the four brands equally, for there was insufficient evidence of a shade-brand interaction. The shade variation was significantly lower for the A2, A3.5, and C2 samples compared with the D4 samples.

For the body/opaque samples, there was no significant difference in the color variation among the six shades of porcelains, but the variation among brands was significant at the 0.05 level. The shade-brand interaction was also sig- nificant-that is, the effect of brand on color variation was shade-dependent. The Vita, Will-Ceram, and Ceramco samples had significantly lower shade variation than the Jelenko samples.

Color Variations for Three Batches of Body/Opaque Samples.-The color variations for the three batches of the combined body/opaque samples (after three firings) are given in Table 3 . The overall mean color variation was 1.44 . There was a highly significant brandshade interaction. The Vita samples had a color variation lower than that of the Ceramco, Will-Ceram, or Jelenko samples. Shade A3.5 had higher color variations between batches than did shades $\mathrm{D} 4, \mathrm{~A} 2, \mathrm{~B} 2$, or $\mathrm{A} 3$.

Color Changes Due to Multiple Firing.-Color differences based upon the third firing as the standard compared with the sixth firings are given in Table 4 . This would represent the situation of the porcelain being overfired. The mean color difference as a result of multiple firings was 1.00 after six firings, compared with the color after three firings. When grouped by brand, Vita and Ceramco showed less color change after six firings than did Jelenko or WillCeram. There was no significant difference when samples were grouped by shade at the $95 \%$ confidence level.

\section{DISCUSSION}

The interpretation of these color differences is based upon two visual matching studies. Ruyter etal. (1987) and Johnston and Kao (1989) found that color differences of 3.3 and 3.7 , respectively, were acceptable for resin composites. With these used as criteria, the color differences reported in this study would be acceptable.

Shade Variation.-The body/opaque samples had a greater shade variation (with a range of from 0.49 to 1.56) than did the opaque samples alone (with a range of from 0.20 to 1.00 ). This is to be expected, since an opaque sample is closer to an ideal sample for spectrophotometric measurements, since only the surface is being measured. With translucent samples, light would penetrate below the surface of the sample, and therefore more variation in the measurements would be expected.

Color Variations for Three Batches of Body/Opaque Samples. - The color variation ranged from 0.55 to 3.38 , depending on the shade and brand. Jelenko porcelain showed the greatest batch 
variation and Vita the least. This represented the factor contributing the most toward color changes that was measured in this study. It supports the recommendation that custom shade tabs be prepared for different batches of porcelain.

Color Changes Due to Multiple Firings.-For this study, three firings were chosen for the baseline measurements, and additional measurements were made after a sixth firing. The actual number of firings will vary from laboratory to laboratory, and from case to case.

Color differences as a result of multiple firings were greater for certain brands. The average color difference between three and six firings was 1.00 . In general, however, these color differences were lower than expected, which supports Jorgenson and Goodkind's findings (1979) that repeated firings (up to 10 times) did not noticeably affect the color stability of any shade tested.

\section{ACKNOWLEDGMENTS}

The authors would like to express their appreciation to Ceramco, Inc., Jelenko Dental Health Products, Vident Products, Inc., and Williams Dental Co., Inc., for the donations of porcelains for this study.

\section{REFERENCES}

BARGHI, N. (1982): Color and Glaze: Effects of Repeated Firings, $J$ Prosthet Dent 47:393-395.

BARGHI, N. and GoldBERG, J. (1977): Porcelain Shade Stability after Repeated Firing, J Prosthet Dent 37:173175.

BARGHI, N.; PEDRERo, J.A.F.; and BosCh, R.R. (1985): Effects of Batch Variation on Shade of Dental Porcelain, $J$ Prosthet Dent 54:625-627.

BARGHI, N. and RICHARDSON, J.T. (1978): A Study of Various Factors Influencing Shade of Bonded Porcelain, $J$ Prosthet Dent 39:282-284.

Binns, D. (1977): The Physical and Chemical Properties of Dental Porcelain. In: Dental Porcelain: The State of the Art-1977, H.N. Yamada, Ed., Los Angeles: University of Southern California School of Dentistry, pp. 25-34.

JOHNSTON, W.M. and KAO, E.C. (1989): Assessment of Appearance Match by Visual Observation and Clinical Colorimetry, J Dent Res 68:819-822. JoRGENSON, M.W. and GOODKIND, R.J.

TABLE 1

MEAN COLOR VARIATIONS ( $\triangle E$ ) OF A SINGLE BATCH OF OPAQUE PORCELAINS WITH TUKEY GROUPINGS FOR ALPHA $=0.05(\mathrm{~N}=6)$ (FIRED THREE TIMES)

\begin{tabular}{|c|c|c|c|c|c|c|c|}
\hline \multirow[b]{2}{*}{ Brand } & \multicolumn{6}{|c|}{ Shade } & \multirow[b]{2}{*}{ Mean } \\
\hline & D4 & $\mathrm{B} 2$ & $\mathrm{~A} 3$ & A3.5 & $\mathrm{C} 2$ & $\mathrm{~A} 2$ & \\
\hline Will-Ceram & 1.00 & 0.36 & 0.53 & 0.51 & 0.34 & 0.47 & 0.54 \\
\hline Ceramco & 0.53 & 0.63 & 0.61 & 0.34 & 0.45 & 0.20 & 0.46 \\
\hline Vita & 0.78 & 0.70 & 0.22 & 0.41 & 0.32 & 0.24 & 0.44 \\
\hline Jelenko & 0.53 & 0.30 & 0.39 & 0.35 & 0.35 & 0.49 & 0.40 \\
\hline \multirow[t]{2}{*}{ Mean } & 0.71 & 0.50 & 0.44 & 0.40 & 0.36 & 0.35 & 0.46 \\
\hline & & & & & & \multicolumn{2}{|c|}{ ANALYSIS OF VARIANC } \\
\hline Source & Sum of Squares & DE & leg. of Freedom & \multicolumn{2}{|c|}{ Mean Square } & F-Ratio & Prob $>F$ \\
\hline Between Brand & 0.324 & & 3 & \multicolumn{2}{|l|}{0.108} & 0.93 & 0.4306 \\
\hline Between Shade & 2.145 & & 5 & \multicolumn{2}{|l|}{0.429} & 3.68 & 0.0039 \\
\hline Interaction & 2.407 & & 15 & \multicolumn{2}{|l|}{0.160} & 1.38 & 0.1696 \\
\hline Error & 13.869 & & 119 & \multicolumn{3}{|l|}{0.117} & \\
\hline
\end{tabular}

TABLE 2

MEAN COLOR VARIATIONS ( $\triangle E$ ) WITHIN THREE BATCHES OF BODYIOPAQUE SAMPLES WITH TUKEY GROUPINGS FOR ALPHA $=0.05(\mathrm{~N}=18)$ (FIRED THREE TIMES)

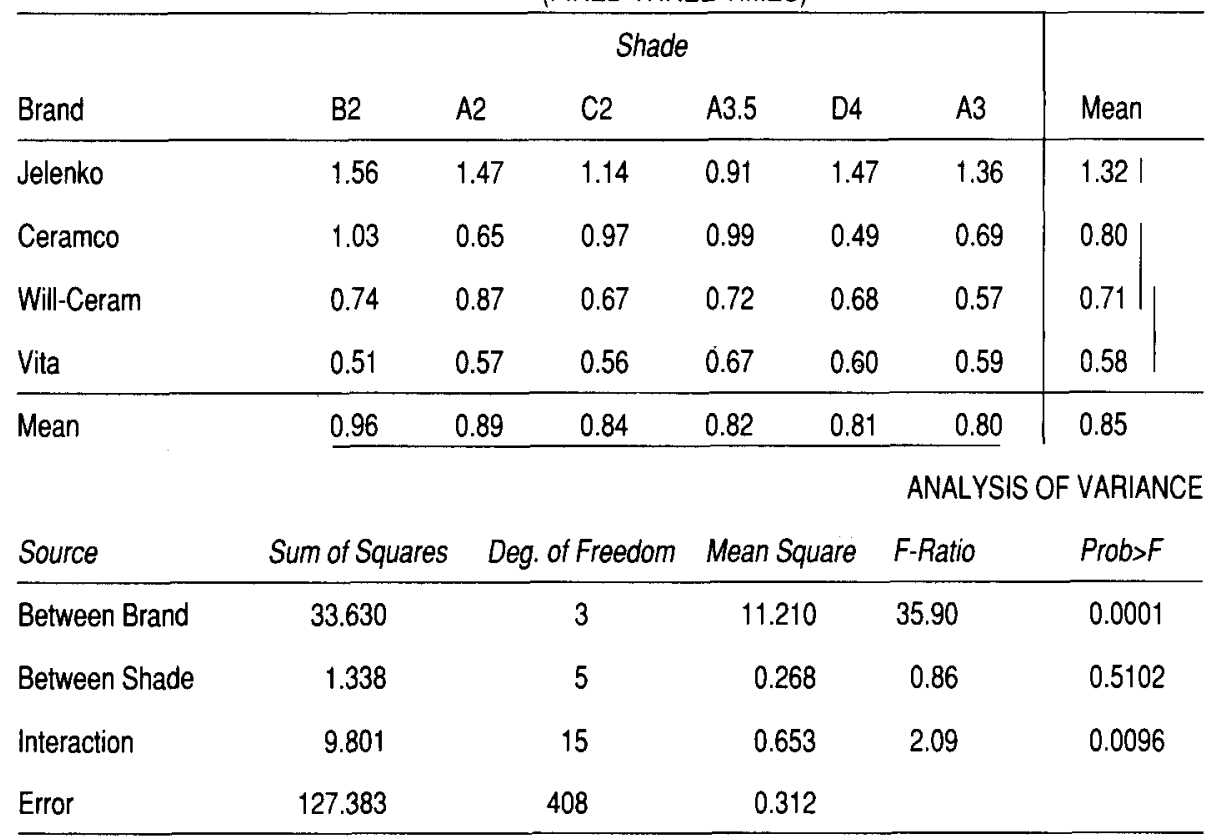

(1979): Spectrophotometric Study of Five Porcelain Shades Relative to the Dimensions of Color, Porcelain Thickness, and Repeated Firings, $J$ Prosthet Dent 42:96-105.

KuEHNI, R.G. and MarCus, R.T.(1979): An Experiment in Visual Scaling of Small Color Differences, Color Res Appl 4:83-91.
MILLER, L. (1987): Organizing Color in Dentistry, J Am Dent Assoc Special Issue Dec:26-40.

PRESTON, J.D. (1983): The Elements of Esthetics-Applications of Color Science. In: Dental Ceramics-Proceedings of the First International Symposium on Ceramics, J.W. McLean, Ed., Chicago: Quintes- 


\section{TABLE 3}

COLOR VARIATIONS ( $\triangle E$ ) FROM THE MEAN COLOR OF BODY/OPAQUE SAMPLES FOR THREE DIFFERENT BATCHES WITH TUKEY GROUPINGS FOR ALPHA $=0.05(\mathrm{~N}=18)$ (FIRED THREE TIMES)

\begin{tabular}{|c|c|c|c|c|c|c|c|}
\hline \multirow[b]{2}{*}{ Brand } & \multicolumn{6}{|c|}{ Shade } & \multirow[b]{2}{*}{ Mean } \\
\hline & A3.5 & $\mathrm{C} 2$ & D4 & $\mathrm{A} 2$ & B2 & $A 3$ & \\
\hline Jelenko & 3.38 & 3.17 & 1.73 & 2.03 & 1.69 & 1.75 & 2.291 \\
\hline Will-Ceram & 2.40 & 1.08 & 1.54 & 1.08 & 1.27 & 0.84 & 1.37 \\
\hline Ceramco & 1.43 & 1.71 & 1.10 & 0.90 & 1.65 & 0.97 & 1.29 \\
\hline Vita & 0.70 & 0.59 & 0.91 & 1.18 & 0.55 & 0.92 & 0.811 \\
\hline \multirow[t]{2}{*}{ Mean } & 1.97 & 1.64 & 1.32 & 1.30 & 1.29 & 1.12 & 1.44 \\
\hline & \multicolumn{7}{|c|}{ ANALYSIS OF VARIANC } \\
\hline Source & Sum of Squares & \multicolumn{2}{|c|}{ Deg. of Freedom } & \multicolumn{2}{|c|}{ Mean Square } & F-Ratio & Prob $>F$ \\
\hline Between Brand & 123.961 & & 3 & 41.321 & & 61.14 & 0.0001 \\
\hline Between Shade & 34.831 & & 5 & 6.966 & & 10.31 & 0.0001 \\
\hline Interaction & 63.055 & & 15 & 4.204 & & 6.22 & 0.0001 \\
\hline Error & 275.719 & & 408 & 0.676 & & & \\
\hline
\end{tabular}

TABLE 4

COLOR DIFFERENCE ( $L$ E) BETWEEN THE MEAN COLORS OF BODY/OPAQUE SAMPLES AFTER MULTIPLE FIRINGS (SIX TIMES) WITH TUKEY GROUPINGS FOR ALPHA $=0.05(\mathrm{~N}=1)$ (BASED UPON BEING FIRED THREE TIMES AS THE STANDARD)

\begin{tabular}{|c|c|c|c|c|c|c|c|}
\hline \multirow[b]{2}{*}{ Brand } & \multicolumn{6}{|c|}{ Shade } & \multirow[b]{2}{*}{ Mean } \\
\hline & A3.5 & A3 & $\mathrm{A} 2$ & $\mathrm{D} 4$ & $\mathrm{C} 2$ & B2 & \\
\hline Jelenko & 1.48 & 1.56 & 1.22 & 1.84 & 1.42 & 1.18 & 1.45 \\
\hline Will-Ceram & 2.07 & 1.31 & 1.20 & 0.97 & 1.40 & 1.63 & 1.43 \\
\hline Vita & 0.38 & 1.22 & 1.08 & 0.31 & 0.25 & 0.26 & 0.58 \\
\hline Ceramco & 1.01 & 0.72 & 0.38 & 0.51 & 0.49 & 0.16 & 0.54 \\
\hline Mean & 1.24 & 1.20 & 0.97 & 0.91 & 0.89 & 0.81 & 1.00 \\
\hline
\end{tabular}

sence Pub. Co., Inc., pp. 491-520.

PREston, J.D. (1985): Current Status of Shade Selection and Color Matching, Quint Int 16:47-58.

RUYTER, I.E.; NiLNER, K.; and Moller, B. (1987): Color Stability of Dental Composite Resin Materials for Crown and Bridge Veneers, Dent Mater 3:246-251.

Wyszecki, G. and Stiles, W.S. (1982): Color Science. Concepts and Methods. Quantitative Data and Formulae. New York: John Wiley and Sons. 